\title{
Long-term frozen storage of stem cells: challenges and solutions
}

\section{David T Harris ${ }^{1-5}$}

'University of Arizona Health Sciences Biorepository, ${ }^{2}$ Department of Immunology, ${ }^{3}$ Division of Translational Medicine, ${ }^{4}$ GMP Laboratory, University of Arizona, Tucson, ${ }^{5}$ Celebration Stem Cell Centre, Gilbert, AZ, USA
Correspondence: David T Harris University of Arizona, PO Box 245221, Tucson, AZ 85724, USA

Tel + I 5206265127

Email davidh@email.arizona.edu

\author{
This article was published in the following Dove Press journal: \\ Journal of Biorepository Science for Applied Medicine \\ 7 luly 2016 \\ Number of times this article has been viewed
}

\begin{abstract}
Stem cells are found in all multicellular organisms and are defined as cells that can differentiate into specialized mature cells as well as divide to produce more stem cells. Stem cells are commonly harvested for clinical and research applications from bone marrow, peripheral blood, umbilical cord blood and tissue, and adipose tissue. These sites are easily accessible and economical to harvest and contain large numbers of stem cells. The advent of modern cryopreservation technology introduced the concept of harvesting and banking stem cells for future use to avoid issues with donor attrition. Large-scale stem cell banking really began in earnest in the 1990s with the establishment of umbilical cord blood banks, which gradually expanded to include cord tissue and finally adipose tissue. Banked stem cells of all origins not only are used for research but are commonly utilized for clinical applications that include transplantation and regenerative medicine. Many of these stem cell sources have been utilized after cryopreservation, which is the subject of this review. Often the stem cells are stored for varying periods of time which may range from weeks to years (even decades) and are often stored in multiple aliquots (which may vary in size) in order to make the stem cell samples more amenable to multiple uses. There is a considerable investment of time and money into these endeavors as it can directly impact patient safety. Each stem cell source has its own particular challenge(s), although there is some overlap, demanding its own particular requirements to achieve a solution. This review will cover the challenges and unique requirements involved in collection, processing, cryopreservation, storage, thawing, and quality control for each of the most commonly used stem cell sources (bone marrow, cord blood, mobilized peripheral blood stem cell, cord tissue, and adipose tissue).
\end{abstract}

Keywords: stem cells, banking, cryopreservation, regenerative medicine

\section{Introduction}

Stem cells are found in all multicellular organisms and are defined as cells that can differentiate into specialized mature cells as well as divide to produce more stem cells. Stem cells can be divided into embryonic/fetal stem cells and adult stem cells, on the basis of their origin. Stem cells can be further classified as totipotent, capable of giving rise to all tissues in the organism including the organism itself; as pluripotential, able to give rise to multiple lineages of tissues and cells from different germ lineages; as multipotential, which can give rise to different cell types generally within the same germ lineage; and as progenitor cells, which only give rise to more lineage-restricted cells and tissues from a single germ layer origin. Hematopoietic stem cells (HSCs) were first proposed and later characterized by Till and $\mathrm{McCulloch}^{1-2}$ based on work submit your manuscript | www.dovepress.com
Journal of Biorepository Science for Applied Medicine 2016:4 9-20

(c) (7) (5) 2016 Harris. This work is published and licensed by Dove Medical Press Limited. The full terms of this license are available at https://www.dovepress.com/terms. BY NG php and incorporate the Creative Commons Attribution - Non Commercial (unported, v3.0) License (http:///creativecommons.org/licenses/by-nd/3.0/). By accessing the work you hereby accept the Terms. Non-commercial uses of the work are permitted without any further permission from Dove Medical Press Limited, provided the work is properly attributed. For permission for commercial use of this work, please see paragraphs 4.2 and 5 of our Terms (https://www.dovepress.com/terms.php). 
performed in the early 1950s and 1960s. HSCs were defined as multipotential cells capable of giving rise not only to every hematopoietic cell lineage in the organism (eg, monocytes, platelets, red blood cells [RBCs], and lymphocytes) but also to additional HSCs that could provide perpetual blood cell production over the course of an individual's lifetime (defined as hematopoiesis). Based in part on these seminal discoveries and the realization that HSCs could be harvested from the long bones of the body without adverse effects to the donor, HSCs were clinically utilized by E Donnell Thomas in New York in 1957 for the first (syngeneic) bone marrow transplant (BMT) to treat a cancer patient using bone marrow (BM) HSC from an identical twin, ${ }^{3}$ which was followed by work from RA Good at the University of Minnesota using HSCs in the first allogeneic (related) BMT for a nonmalignant condition in 1968. ${ }^{4} \mathrm{HSCs}$ have since had a long history of clinical use. Additional successful BMT resulted in the establishment of the National Marrow Donor Program in the mid-1980s in an effort to facilitate increased numbers of BMT treatments and to standardize the donor/patient matching procedure. The National Marrow Donor Program serves as a conduit for matching BM donors to patients in need, but neither collects nor stores HSCs (all matching is done electronically and donors are referred to medical centers for HSC harvest when needed). The advent of modern cryopreservation technology during the 1980s introduced the concept of harvesting and banking HSC for future use to avoid issues with donor attrition that has plagued the National Marrow Donor Program since its inception. However, it was not until the early 1990s that HSC banking, in the form of umbilical cord blood (CB) banking came to fruition in response to the first successful CB transplant for a child with Fanconi anemia in $1988 .^{5}$ Commercialization of this endeavor rapidly followed with the first family CB bank being established at the University of Arizona in 1992 (which later became the Cord Blood Registry $^{6}$ ) and the first public CB bank established 6 months later at the New York Blood Center (also in 19927). Both of these early CB banks remain in existence today (which has not always been true for other CB banks) and are the largest CB banks of their kind in existence (greater than 600,000 and 200,000 samples, respectively). CB banking simplifies the issues of locating HSC donors in times of need, prevents donor attrition, and has reduced the overall health care costs. Since its first clinical use in 1988 and since CB banking's inception in 1992, banked CB samples have been used in more than $35,000 \mathrm{CB}$ transplants as of $2015 .{ }^{8}$ However, with more than 5 million CB samples banked worldwide, its overall utilization rate is low $(<1 \%$ of banked samples have ever been used). Fortunately, during the time that CB transplantation was being integrated into routine BMT therapies, it was observed that donor-derived neural cells were present in the brains of transplant patients upon autopsy. These observations led to speculation that HSCs might be able to give rise (albeit at low numbers) to cells and tissues outside the normal HSC germ lineage. ${ }^{9}$ That is, the nervous system is derived from the ectoderm germ layer while HSCs are derived from the endoderm germ layer. It was also at this time that embryonic stem cells were discovered and characterized by investigators at the University of Wisconsin, ${ }^{10}$ who hypothesized that these stem cells might be used to treat a gamut of diseases by using them in cellular therapies, giving rise to the fields of tissue engineering and regenerative medicine. It was not long before investigators at Duke University and elsewhere ${ }^{11,12}$ investigated whether HSCs might be used for these types of clinical applications. Based on the ease and costs of procurement, CB-derived HSCs were one of the first stem cell sources that were analyzed. However, BMderived stem cells, both HSCs and mesenchymal stromal cells (MSCs), have also been investigated as other MSC sources such as cord tissue (CT) and adipose tissue (AT). As with stem cell samples stored in CB banks, many of these stem cell sources have been utilized after cryopreservation, which is the subject of this particular review. Often the stem cells are stored for varying periods of time which may range from weeks to years (even decades) and are often stored in multiple aliquots (which may vary in size) in order to make the stem cell samples more amenable for multiple purposes. These particular demands come with their own challenges and have required unique and novel solutions. Both the institution storing the stem cells and the stem cell end user (and by extension the patient) need to have confidence that the frozen stem cell sample upon thawing and use will act functionally in an identical fashion to freshly obtained cells, regardless of the length of time in frozen storage. Not only is there a considerable investment of time and money into these endeavors, but patient health and patient lives may be at risk if these procedures are done improperly. Each stem cell source has its own particular challenge(s), although there is some overlap, demanding its own particular requirements to achieve a solution. This review will cover the challenges and unique requirements involved in the collection: processing, cryopreservation, storage, thawing, and quality control for each of the most commonly used stem cell sources (BM, CB, mobilized peripheral blood stem cell [PBSC], CT, and AT). 


\section{Stem cell sources}

\section{Bone marrow}

Procurement of clinically relevant numbers of stem cells (both HSCs and MSCs) from BM requires surgical harvesting of large volumes of donor marrow (whether autologous or allogeneic), generally in the range of $1000-1500 \mathrm{cc}$ (to avoid in vitro manipulation/expansion prior to use). The surgical procedure requires general anesthesia with some associated risks of morbidity (and even mortality), resulting in increased costs (upwards of $\$ 30,000$ or more). HSCs comprise $<0.001 \%$ of the total nucleated cells (TNCs) in the BM, whereas MSCs comprise $<0.05 \%$ of the TNCs. ${ }^{13}$ Although MSCs can be expanded in vitro, ${ }^{14}$ HSCs cannot to any great extent and not without significant time and effort, ${ }^{15,16}$ and there is always a concern for expansion-induced cellular senescence. ${ }^{17}$ Due to its method of harvest, there is considerable sample contamination with RBCs that must be removed, as well as physical constraints associated with cryopreserving such large volumes..$^{18}$ Generally, BM is used for stem cell transplant without frozen storage, although at times it may be placed in short-term cryopreservation as a back-up for aplasia sometimes associated with chemotherapy or engraftment failure. However, with the initiation of BM-derived MSC regenerative medicine therapies, processed BM is now being frozen, at least for a short term, for those applications that may require access to multiple aliquots of stem cells for multiple treatments.

\section{Peripheral blood}

Clinical utilization of the cytokines granulocyte $(G)$ and granulocyte-moncyte (GM) colony stimulating factors (CSF) revealed that not only did these cytokines stimulate production of neutrophils in patients exhibiting leukopenia resulting from a variety of causes, but at the same time mobilized HSCs into the peripheral circulation where the cells could be collected for use in stem cell transplantation. ${ }^{19,20}$ Normally, HSCs are not present in any clinically useful numbers in unmobilized PBSCs but upon treatment as many as $0.05 \%$ of the peripheral TNCs may be CD34 ${ }^{+} \mathrm{HSCs}$. As a consequence of how the HSCs are collected, the vast majority of TNCs are PMN, followed by T cells and RBCs. To facilitate biobanking, volume reduction is employed, which generally means RBCs are depleted via a number of different methods. ${ }^{21,22}$ Generally, mobilized peripheral blood mononuclear cells (PBMCs) are used solely for stem cell transplant procedures and have not been used in regenerative medicine or tissue engineering and thus like BM are not routinely cryopreserved (at least not for any significant period of time). Like BM, the large volumes $\left(1 \mathrm{~L}\right.$ or more) and large number of cells (exceeding $10^{10}-10^{11}$ TNCs) pose unique problems for biobanking.

\section{Umbilical cord blood}

Work performed in the 1980 s revealed that umbilical CB, the blood left over in the placenta after a baby was born, was a rich source of HSC $\left(0.5 \%-1 \%\right.$ of the mononuclear cells..$^{23,24}$ Preclinical studies along with early clinical work demonstrated that CB-HSC could be substituted for BM-HSC for use in typical stem cell transplants. ${ }^{23,24} \mathrm{CB}$ presented scientists with the unique opportunity to target HSC donors and cryopreserve the donated biospecimens without having an immediate need for the samples. In essence, CB banking was the first significant foray into large-scale, routine stem cell banking. In addition, CB specimens are normally one-tenth the size of BM or PBSC specimens $(\sim 100 \mathrm{cc})$, simplifying the biobanking process, although as discussed in the next section, volume-reduction is routinely performed to further simplify the process using multiple manual and automated processes..$^{24-27}$ Over the past 20 years, more than 35,000 CB transplants have been performed worldwide and more than 5 million $\mathrm{CB}$ samples have been collected and cryopreserved ${ }^{8}$ (www.bethematch.org).

\section{Umbilical cord tissue}

Although MSCs have long been studied as a clinically relevant source of stem cells ${ }^{28}$ (primarily BM-derived) and have been extensively studied in multiple regenerative medicine and tissue engineering applications, ${ }^{29,30}$ it was not until recently that the umbilical cord (specifically the Wharton's jelly contained within the tissue; $\mathrm{CT}$ ) itself was recognized as an economical and readily available source of large numbers of MSCs. ${ }^{31,32}$ Similar to AT as in discussed in the "Adipose tissue" section, CT presents unique problems for biobanking in that it is a whole tissue, not a cell suspension. Although the tissues could be processed as described in the "Adipose tissue" section to facilitate the cryopreservation process, by doing so additional regulatory issues arise, which must be addressed. However, as one of the youngest sources of MSCs available (similar to CB-HSCs), its inclusion into any stem cell banking program is worthwhile.

\section{Adipose tissue}

Research studies performed in the past decade have demonstrated that subcutaneous AT is the richest source of MSCs in the human body, containing 100-1,000 $\times$ more MSCs/ gm or cc of either BM or $\mathrm{CT}^{33,34}$ In fact, as many as $1 \%$ of all TNCs contained within AT may be MSCs. ${ }^{33,34}$ AT-MSCs have been the focus of hundreds of clinical trials, and hundreds (if not thousands) of patients have been treated using AT-MSCs, showcasing their importance for any stem cell biobanking effort. However, similar to CT, AT is a tissue 
and not a cell suspension posing unique constraints on its banking. In fact, lipoaspirate, which is often the starting point for AT-MSC collection, is a viscous gelatinous tissue that is difficult to manipulate, even at room temperatures. Although the lipoaspirate could be digested/processed similar to AT, such a procedure would necessarily require imposition of additional and somewhat onerous regulatory guidelines. The physical characteristics of the biospecimen also present unique requirements while thawing, washing, and clinically using the banked sample.

\section{Stem cell collection}

Whenever possible it is desirable to utilize a closed and sterile system for stem cell collections, which simplifies many regulatory requirements. If the collection system can also be used for the processing procedures (including cryopreservation), it is even more attractive to the user. Finally, as most stem cell collections will be performed by clinicians who may or may not have extensive experience in stem cell collection, the harvest system should be easy to use without extensive previous training. Although all collection systems are sterile, sometimes the collection options (closed systems that are simple to operate) are limited by the particulars of the stem cell source as discussed in each of the following sections.

\section{Bone marrow}

BM-derived HSCs are generally collected through a surgical procedure utilizing large syringes in a semi-closed system. During the collection, the syringe is used to draw marrow and blood from the large sinus in the hips and pooled. Generally, 100--200 syringe "pulls" are performed resulting in 1,000-1,500 cc of blood and marrow being obtained. Similar approaches are used for BM-MSC collection, although collection volumes rarely exceed $200 \mathrm{cc}$ because of the ability to expand MSCs easily in culture.

\section{Mobilized peripheral blood}

PBMCs are collected by leukopheresis after subjects have been treated for 3-5 days with G-CSF, GM-CSF, or another mobilizing agent. That is, the subjects are connected to a machine for 1-3 days for several hours per day, which removes excess white blood cells (including stem cells) from the peripheral circulation while returning RBCs and plasma back to the donor. Collections are made using closed systems that can be connected sterilely to closed, automated processing systems. Generally, bags are used that can range from 300 to $2,000 \mathrm{cc}$ in volume, and they are available commercially with either EDTA or CPD as an anticoagulant.

\section{Umbilical cord blood}

Several options exist in terms of CB collection. The most commonly used approaches employ 300-cc blood bags (containing EDTA, CPD, or heparin) or 60-cc syringes containing heparin. $\mathrm{CB}$ is unique in that stem cell harvests are performed by obstetricians who may have little surgical training and require simple, reliable collection systems. Both bags and syringes are closed collection systems. The collection bags depend on gravity to fill, while the syringes require a "hands-on" interaction to be successful. Most stem cell banks collect $\mathrm{CB}$ using the bag approach, although many $\mathrm{CB}$ banks have also used the syringe approach due to its economy (syringes cost pennies to purchase). Both the approaches generally collect $\sim 100 \mathrm{cc}$ of $\mathrm{CB}$ that is routinely sterile and clinically useful. Most of the institutions provide specially designed collection kits to their obstetricians which are sterile and contain all necessary provisions to make a successful collection (Figure 1).

\section{Cord tissue}

Collection of CT is a recent development in the stem cell field. By its nature, CT is not sterile (at least the exterior) and cannot be collected in a closed system. Normally, the obstetrician will cut a 6- to 10-inch segment of the umbilical cord after birth of the child and its ligation. The segment of the cord is then placed into a sterile capped cup (eg, urine specimen cup) that contains a transport buffer (as well as antibiotics and antifungals). Care must be taken to ensure that the CT is not exposed to excessive air and is kept "wet" (submerged) during transport.

\section{Adipose tissue}

AT may be collected either as a by-product of a liposuction procedure or through an independent stand-alone procedure. Both the approaches utilize syringes (either large 60-cc syringes that can connect to a liposuction canister or small 20-cc syringes for the manual procedure). Both the collection systems can be considered "closed". Furthermore, if desired, the syringes can be sterilely connected in a closed fashion to large bags for processing and storage (depending on the desired volumes). As an add-on to a liposuction procedure, it is possible to obtain several liters of lipoaspirate (although most banks collect no more than 2,000 cc). As a stand-alone procedure performed under local anesthetic, harvests are normally no larger than 20-100 cc.

Once a stem cell source has been collected, it needs to be transported to the processing facility, whether locally or over long distances. Transport is generally performed using 

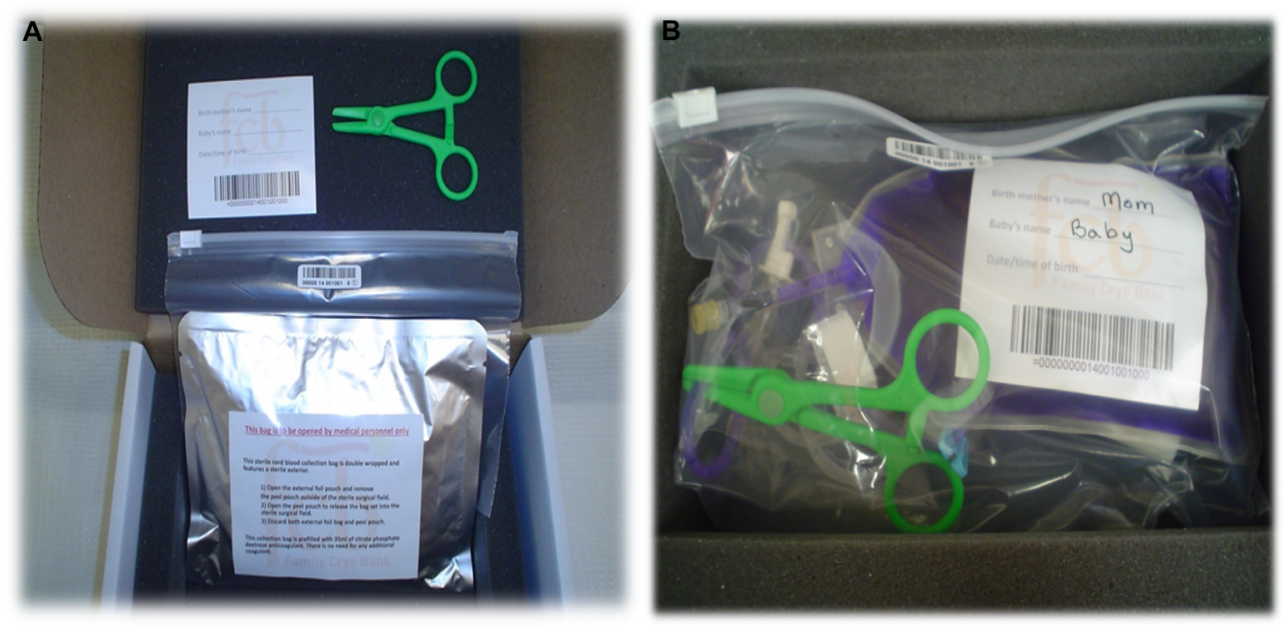

Figure I A typical (cord blood) stem cell collection kit and shipping container.

Notes: The sterile collection pouch containing the collection bag $(\mathbf{A})$ and the necessary equipment needed to collect and ship a cord blood collection (B).

a courier service or by a member of the banking facility (if local). Care needs to be taken to ensure that the stem cells do not "spill" during transport, do not suffer excessive temperature fluctuations, and arrive for processing within 24 hours of collection. Local deliveries are generally performed using coolers packed with "blue ice" blocks. Overnight deliveries utilize specialized shipping containers that are crush-resistant, doubly contained, and insulated against temperature swings. At times it may be worthwhile to consider the placement of temperature loggers within shipping containers to ensure viability of the samples and to validate procedures.

\section{Stem cell processing}

The purpose of stem cell processing is to reduce sample volume and enrich stem cell/progenitor cell content while maintaining reliability and throughput. Figure 2 illustrates an example for $\mathrm{CB}$ processing outcomes. Different approaches are used for different stem cell sources.

\section{PBSC and bone marrow}

Both PBMC and BM are processed similarly due to the large volumes of samples that are involved $(\sim 1-1.5 \mathrm{~L})$. Although it is possible to process these large volumes manually (eg, using Ficol density gradients and centrifugation) to remove RBCs and reduce volumes, generally it is impractical. Thus, almost uniformly automated processing devices are utilized to obtain stem cells in clinically applicable sizes. Such devices include ones obtained from Haemonetics, Fenwall, CliniMacs, and COBE. Each of these automated machines operates in a closed system, and the end-products are Food and Drug Administration (FDA)-approved for clinical use.

\section{Umbilical cord blood}

Universally, CB is processed in a closed system. Multiple methods exist whereby this can be accomplished, including automated and manual approaches. In the early days of CB banking, collected samples were prepared for banking by either plasma depletion ${ }^{35}$ or by treatment with Hespan. ${ }^{36}$ Both the approaches are considered "open" methods of processing although steps can be taken to "close" these systems. They also result in some reduction of overall sample volume, although plasma depletion does not remove RBCs, which can be problematic upon sample thawing and infusion. Plasma depletion essentially involves preparation of a buffy coat of leukocytes that strenuously can result in $>90 \%$ depletion of RBCs. These issues can also be addressed by using density separation media such as Ficol, ${ }^{37}$ which results in $>90 \%$ mononuclear cells and $\mathrm{CD} 34^{+}$cell recovery with $>85 \% \mathrm{RBC}$ depletion. However, this approach is labor intensive and somewhat expensive, but proven in the clinic.

The major issue with all manual methods is reproducibility and sample throughput. To address these issues, two companies introduced automated $\mathrm{CB}$ processing devices. Thermogenesis introduced the AXP platform for CB processing, and BioSafe introduced the Sepax method for $\mathrm{CB}$ banking. Both the methods result in a cell product of $\sim 20-25$ $\mathrm{mL}$ that is easily banked in compartmentalized bags, which is economical. However, the AXP approach produces a product with fewer RBC and greater TNC recovery, comparable to what is observed with a Ficol approach. Table 1 provides the comparison of outcomes with different processing methodologies. Both the approaches increase sample throughput while keeping labor costs down and ensure reproducibility that translates into increased reliability. 


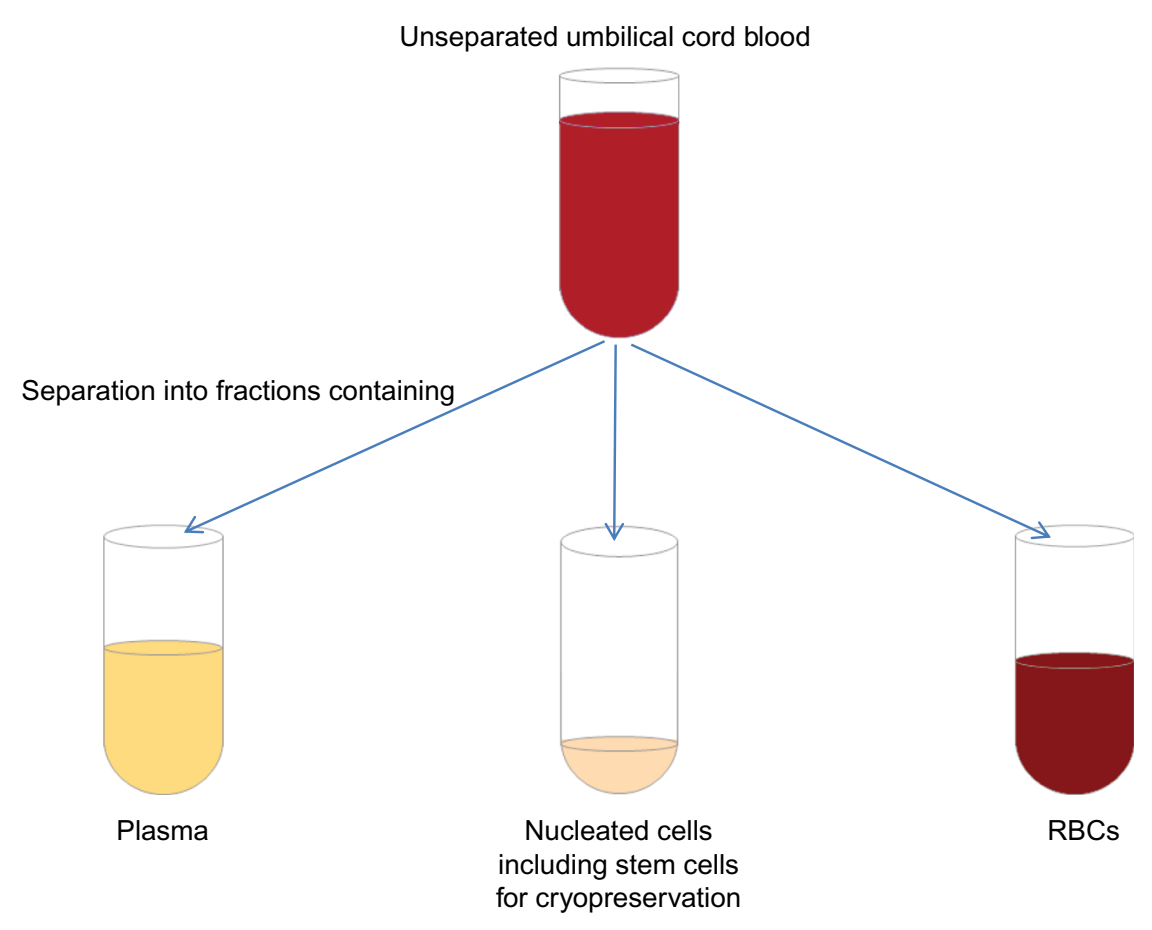

Purpose of processing:

Volume reduction

80-100 cc down to $20-25 \mathrm{cc}$

Less DMSO required for freezing

Increased storaged capacity

Increased economy
RBC depletion

Increased sample viability

Decreased hemoglobinuria

Decreased ABO incompatibility

Easier infusions

Figure 2 Schematic representation of cord blood processing outcomes. Abbreviations: DMSO, dimethyl sulfoxide; RBC, red blood cell.

It should be noted that the plasma depletion approach can be performed inexpensively using syringes, allowing for a closed system of collection, processing, and cryopreservation although more manual input is required than when using the Sepax methodology. However, the syringe approach costs $\sim$ \$50 per sample to process compared with $\$ 2-\$ 300$ per sample for other approaches.

\section{Umbilical cord tissue}

CT is processed in an "open" fashion because of the nature by which it is harvested and its structural components, whether stored as whole tissue or enzymatically processed to its cellular components (this latter approach would be classified as more than minimally manipulated for regulatory concerns). Therefore, extensive sterility testing (bacterial, fungal, and mycobacterial) is necessary. The stem cells of interest, the MSC, lie within the CT (either as perivascular cells or contained within the Wharton's jelly ${ }^{31,32}$ ), and this anatomical distribution must
Table I Cord blood cell recovery by processing methodology

\begin{tabular}{llll}
\hline & AXP & Hespan & Sepax \\
\hline TNC recovery (\%) & 96 & 78 & 80 \\
MNC recovery (\%) & 94 & 81 & 80 \\
\hline
\end{tabular}

Abbreviations: TNC, total nucleated cell; MNC, mononuclear cells.

be taken into consideration while processing and banking the stem cells. If one attempts to cryopreserve the whole, intact tissue, the MSCs will be damaged and will not survive the process. Thus, one must either finely mince the tissue before cryopreservation ${ }^{38}$ or enzymatically digest the tissue and then freeze the released MSCs as typically done for a single-cell suspension. ${ }^{31,32}$ Finely minced tissue requires the slow infusion of dimethyl sulfoxide (DMSO) over prolonged periods of time to ensure homogenous distribution of the cryoprotectant throughout the tissue. ${ }^{39}$ Isolated MSCs can be frozen for any single-cell suspension. However, two problems are presented with either 
methodology. If one digests the tissue before freezing, it is now considered more than minimally manipulated by the FDA, requiring an investigational new drug (IND) prior to clinical use. Cryopreserved whole, minced CT meets the regulatory definition of minimal manipulation, but one generally recovers only $\sim 10 \%$ of starting cells, requiring extensive ex vivo expansion prior to clinical use (again requiring an IND prior to clinical utilization). CT is problematic to thaw as the tissue itself serves as a sink for the cryoprotectant DMSO, making it difficult to be removed thoroughly, resulting in a loss of viable cells. Thus, CT is a less than optimal stem cell source for clinical applications due to regulatory oversight that is necessary for its use.

\section{Adipose-derived stem cells}

Adipose-derived stem cells have unique processing requirements in that the cells are not obtained from a cellular suspension such as $\mathrm{CB}, \mathrm{BM}$, or PBMC, but contained within a fairly viscous tissue composed of multiple cell types. The goal of processing is to remove as much tumescent fluid as possible along with any contaminating blood, leaving the AT containing the MSCs amenable for immediate cryopreservation or clinical use, or as a source of MSCs after enzymatic digestion. However, it can be processed sterilely in a closed system using either manual or automated methods. Methodology has been developed, which allows for economical, closed system processing that meets FDA requirements for minimal manipulation utilizing modified syringes. ${ }^{40}$ Automated approaches to processing can be found with companies such as BioSafe, GDP Inc., Cytori, and American Cryostem. The automated approaches tend to be more expensive, requiring the purchase of machinery and/or expensive consumables. However, these approaches do increase throughput and are very much reproducible. In addition, being a closed system, these methodologies are compliant with FDA regulations and minimize the risks of sample contamination. All of these systems are closed systems from start to finish, harvest to cryopreservation, including the thawing of the sample after storage. The other difference between the manual systems and the automated systems is that the automated systems produce a stromal vascular fraction after enzymatic digestion which by definition is manipulated and requires an IND from the FDA before clinical use. The manual system produces "enhanced fat" that is minimally manipulated and can be immediately used for cosmetic and reconstructive purposes or processed further under IND for regenerative medicinal applications.

\section{Cryopreservation methods}

Successful banking of stem cells over the long term is critically dependent on the methodology used for cryopreservation. Most, but not all, biobanks that freeze viable stem cells make use of controlled-rate freezers available from numerous commercial entities (eg, Custom Biogenic Systems, Thermo-Fisher, and Thermogenesis ${ }^{37}$ ). Such devices provide computer-controlled precise gradual decreases in temperature to avoid ice crystal formation inside the cells and produce the highest level of viable cells upon storage and later thaw. In addition, such devices provide both hard-copy and electronic records of the actual freeze run, which can be critical when undergoing internal or external audits and inspections (for regulatory licensing), as well as when one tries to determine root cause(s) for any discrepant outcomes with the final cell product. Finally, use of such machines in high-throughput biobanks is essential to minimize costs and maximize sample throughput, while ensuring reliable and reproducible results. The drawback is that each machine can cost upwards of $\$ 15,000$ and may require purchase of two such machines in order to have a back-up device for this critical piece of equipment. These devices are ideal for both bag and vial storage and easily accommodate dozens of bags and up to hundreds of vials during a single cryofreeze run.

However, for biobanks with less capital available and/or fewer daily samples to cryopreserve, alternatives are available. ${ }^{41}$ Although simple and lack in any sort of documentation of the actual freezing run parameters, it is possible to obtain good results (especially for more hardy cells such as MSCs) using devices as simple as Styrofoam containers (eg, Mr Frosty sold by Biocision). Using a step-down approach, one can place cells inside the container and then place the sample at $-80^{\circ} \mathrm{C}$, and then 24 hours later into the vapor phase of a LN2 dewer. Although much easier to accomplish using cryovials, it is not impossible to perform this approach with cryobags (although it does require purchase of bag cassettes). This approach is deceptively easy, a bit more economical and does require less technician time at the end of the processing day to get the samples into the freezers.

\section{Stem cell banking}

Stem cell banking should minimize costs while maximizing the number of samples that can be stored. It would seem that this goal is most easily accomplished using cryovials where one can store 40,000 or more vials in a single dewer, while storing only 5-10,000 cryobags. However, these figures are sometimes deceptive in that large samples may require 
storage of many vials (although up to $100 \times 10^{6}$ cells $/ \mathrm{mL}$ may be stored in a single vial) when only 1-2 bags would be needed. If multiple aliquots of stem cells are needed for treatment or for research and development, vials may be more optimal despite now having multichamber bags that might be suitable. Thus, the final decision has to be based on ultimate end-needs (eg, number of uses and number of cells).

Both cryovials and cryobags can be obtained in various sizes. Cryovials are available from multiple manufacturers in 2.0 and $4.5 \mathrm{cc}$ sizes. Cryobags can be obtained ranging in size from 25 to $250 \mathrm{cc}$ (although most banks use 25-60 cc sizes). Both the types of storage containers should be overwrapped to prevent cross-sample contamination, protect against LN2 contact, and prevent microbial contamination during thawing. Generally, biobanks will utilize vials when smaller samples or many sample aliquots are needed. Bags are generally used for single and larger samples. When a limited number of sample aliquots are needed, multiple 25 cc bags may be used. The issue of aliquots should not be overlooked as it directly impacts the use of the samples for regenerative medicinal applications, stem cell expansion, gene therapy, and so on. It also avoids the need to freeze/ thaw a sample more than once, which can have a detrimental effect on stem cell function. ${ }^{42}$ Cryobags are now available with two compartments ( $20 \%$ and $80 \%)$, four compartments (25\% each), and five compartments (20\% each). Cryobags are much easier to implement in closed processing systems allowing for collection, processing, cryopreservation, and thawing, as well as patient infusion via sterile attachment of additional bags. Until recently, cryovials were only available as an open system requiring the use of laminar flow hoods or a GMP facility along with multiple sterility checks. However, now closed system cryovials in varying sizes that can be integrated into a closed system of cryopreservation are available. Our experience has been that the closed system vials are difficult to manipulate and may not be suitable for high-throughput labs.

Once a decision has been made on the use of vials versus bags, the next issue that must be addressed is what type of storage device will be used for long-term storage of the samples. Long-term storage (ie, $>1$ year) of viable stem cells should always utilize LN2 dewers as lower temperatures can be achieved and less temperature fluctuation is observed. In addition, LN2 dewers are not dependent on the availability of electricity, which can sometimes be a problem. Mechanical freezers, although now capable of reaching temperatures of $-150^{\circ} \mathrm{C}$, are not as cold as LN2 dewers, experience more temperature fluctuations in different areas of the storage device and experience critical failures (moving parts or electrical supplies) at a higher rate than LN2 dewers (that only require an addition of LN2 [manually or automatically] every week or so; even up to several weeks if the lids are not opened). Although there has been argument in the past over long-term storage of stem cell samples in vapor versus liquid phase LN2 dewers, it is really more of an argument over storage temperature and temperature stability. The latest class of LN2 dewers is now remarkably stable at all positions within the device using a vapor phase environment due to better engineering, with the temperature varying $<10^{\circ} \mathrm{C}$ at any position within the device, maintaining $-196^{\circ} \mathrm{C}$ even with open lids. Older vapor phase dewers were notorious for fluctuating as much as $40^{\circ} \mathrm{C}$ when lids were opened to insert or retrieve samples, damaging samples stored within the zone of fluctuation (ie, near the top of the dewer). It is rare that biobanks store samples in the liquid phase anymore. In addition, vapor phase storage prevents/minimizes cross-sample contamination, prevents LN2 burns of technical personnel, and is more economical.

One should note that although it is possible to purchase automated storage devices (similar to ones sold by GE Healthcare through Thermogenesis), these devices are very expensive, subject to mechanical issues, and generally not as well suited to high-throughput biobanks as the manual system of dewers (sold by Thermo-Fisher, Custom Biogenics Systems, or MVE). Dewers may be obtained in sizes capable of holding almost 10,00025 -cc bags or 40,000 4-cc vials.

\section{Quality systems}

Successful establishment of a stem cell bank requires the implementation of a series of quality systems to meet regulatory requirements and to assure physicians, scientists, and patients that the samples will be useful for either research and development or clinical applications at future times. Besides basic quality control and quality assurance systems that should always be a part of the stem cell bank, consideration must be given to systems monitoring and inventory management software. Quality systems must be put in place to calibrate/ qualify all critical equipment, validate all processes, and ensure technical competence. Importantly, if the purpose of the stem cell bank is to store such samples for many decades, with the goal of successful clinical utilization at later times, thought needs to be given to setting up long-term stability studies. Such studies would not only include determinations of cell counts and viabilities but also assess any phenotypic changes in the stem cell populations, as well as measure stem cell function either directly or using a surrogate indicator. For example, 
for HSCs, one might measure $\mathrm{CD} 34^{+}$cell numbers as well as perform colony-forming unit assays to assess stem changes in cell phenotype and function. While using large storage devices similar to ones described in previous section, care must be given to assessing different locations within the device (top, bottom, and sides) to ensure that there are no "hot" spots in the dewer. If one plans on storing for decades, then one must set up assays that make such assessments over the course of many decades. And, if one stores different types of stem cells within a single device, then each type of stem cell must be assessed separately. Also, as part of the quality systems, one must have back-up dewers in place, so that in case of failure, it should be capable of holding $20 \%$ of total inventory at any one time. For those interested in learning more about these issues, as well as other parts of the basic quality systems, the reader is referred to www.aabb.org, as well as FDA's 21CFR regulations.

\section{Systems monitoring}

It is vital (and required) that all critical equipment need be monitored in case of failure and to ascertain performance status. Rather than hire a full-time individual to record these values manually (which is time consuming and expensive), there are several commercially available systems that could be considered. One of the first such systems designed for this purpose is offered by Rhees, a company with a long history in this field. The Rhees system is one of the more expensive systems available but is quite dependable and flexible. As an alternative, the SmartVue system sold by Thermo-Fisher could be implemented. It costs less than half the Rhees system, is expandable, and can be remotely accessed by computer (but not by smartphone). However, its long-term dependability is not known due to the recent introduction of the system to the field. It has been known to have some technical issues associated with it, and replacement of some specialty monitoring probes can exceed several thousand dollars. However, its software system, like that of the Rhees system, does provide audit trails for regulatory purposes and meets many federal guidelines. Finally, for a fraction of the cost of the other systems, one can purchase a cloud-based (off-site server) system from Minnot that offers most of the same capabilities as seen with Rhees and Thermo-Fisher. However, Minnot does not offer some of the more specialized monitoring systems (such as $\mathrm{CO}_{2}$ probes) that are often required in stem cell facilities. In addition, the reporting software from Minnot is primitive and limited, which might cause regulatory issues, but the data can be easily exported into other Laboratory Information Management System software to overcome this deficiency.

\section{Inventory management software}

Accurate tracking of specimens coming into and out of the stem cell bank is an obvious necessity. Once inventory reaches a critical mass (eg, greater than several thousand samples), automated rather than manual systems must be employed. Several software inventory management systems are commercially available. A fairly rigorous and flexible system is TissueMetrix, a software system that has been used by many pathology departments to manage their specimen inventories. TissueMetrix allows for input of many clinical and laboratory data values, along with direct linkage to electronic medical records. However, the software is slow (being based on off-site servers) and not as user friendly as the ones below. Costs are moderate.

An extremely user-friendly and flexible system is that of StemSoft (offered by Stem Cell Technologies) and has been specifically designed for use in stem cell banks and cell therapy facilities. The software meets all federal regulatory requirements (as do all of the other systems), offering audit trails, consumable inventory management, and so on. It is easy to set up and begin using, but it is the most expensive software systems that have been described here, costing more than $\$ 40,000$.

The last inventory management software worth considering is offered by Freezer Works. The software has been around for some time now, is user friendly, and has some of the best graphic interfaces (for sample management) available. It is also the least expensive of all of the software systems, costing less than $\$ 15,000$. It may not be quite easy to use for cell therapy laboratories or for other lab functions aside from sample storage and tracking, but its ease of use and cost make it an option to consider.

\section{Biospecimen thawing for clinical use (basic steps)}

Recovery of maximal numbers of viable and functional stem cells after cryopreservation and prolonged storage is critical for a stem cell bank's survival. Part of this success is due to the implementation of reproducible methodology to thaw frozen samples. Although all the methods generally employ a rapid thaw of the specimen (whether in vial or bag) until the ice plug becomes "slushy" (at $37^{\circ} \mathrm{C}$ ) followed by dilution and washing out of DMSO with cold media, there are some significant differences in optimal methods based on the type of the sample being thawed. DMSO should be removed as quickly as possible by either dilution and/or washing as DMSO at concentrations of $10 \%$ can be toxic to cells particularly when the sample reaches room temperature. ${ }^{43}$ 
Dilution and rapid washing can be easily accomplished with single-cell suspensions as found with $\mathrm{CB}, \mathrm{PBSC}$, and BM samples. With single-cell solutions, it is important to protect against osmotic shock during the thaw and wash procedures, which may lower viability. This can be easily accomplished through addition of colloid buffers such as Dextran-40 to the thaw and wash medias. ${ }^{7}$ However, this approach will not work with ATs and CTs where the tissues are DMSO sinks and make dilution of the DMSO almost impossible to rapidly accomplish. In these instances, the thawed samples are kept cold $\left(9^{\circ} \mathrm{C}-10^{\circ} \mathrm{C}\right)$ to avoid toxicity, diluted with cold media, and incubated for longer periods of time ${ }^{43}$ on a rocker to extract the DMSO. Often, several such prolonged washings may be needed, and the process should be validated. Once the DMSO concentration has dropped AD to acceptable levels, the sample can then be reconstituted with warmer media for use in assays or for clinical applications. Thawing procedures should be validated to assure maintenance of not only cell viability (and phenotype) but also stem cell function (generally as determined by surrogate assays such as colonyforming units), as the two parameters do not always correlate.

Finally, samples that are to be used clinically should not be collected, washed, or cryopreserved using animal-derived products such as fetal bovine serum unless acquired from qualified lots approved by regulatory agencies. Rather, humanderived products such as human serum albumin that have been tested for the presence of infectious agents are preferred. All the specimens should be manipulated using clinical grade reagents if at all possible (DMSO is an exception). Although more expensive than other types of qualified reagents, use of GMP grade reagents is often required by regulatory agencies.

\section{Long-term stability data}

The purpose of stem cell banks is to acquire and store various types of stem cells for future use. Storage of such samples may be for months, years, or even decades. In order to ensure that such samples will indeed be useful (either for research or clinical applications), all laboratory and banking processes must be validated. These validations must include establishment of long term stability studies, including assessment of both viability and function. It is preferred that the same set of samples be assessed at each time point (rather than using a mixture of samples), which can be accomplished by the banking of multiple aliquots of stem cells early during the initial setup of the cell bank. These aliquots can be removed at various times (eg, annually) and compared to results obtained with the same fresh, never frozen sample tested at an earlier time point. Multiple donors should be used to assess patient variability, generally ten donors for each stem cell type should be aliquoted and banking planned for no less than 20 years.

As seen in Figure 3, adipose stem cells can be stored frozen and later thawed up to 2 years, which still will exhibit comparable biological activity (not statistically significant). Similar findings have been observed for CT MSC as shown in Figure 4. We and others have previously reported and published similar observations for CB HSCs. ${ }^{44,45}$

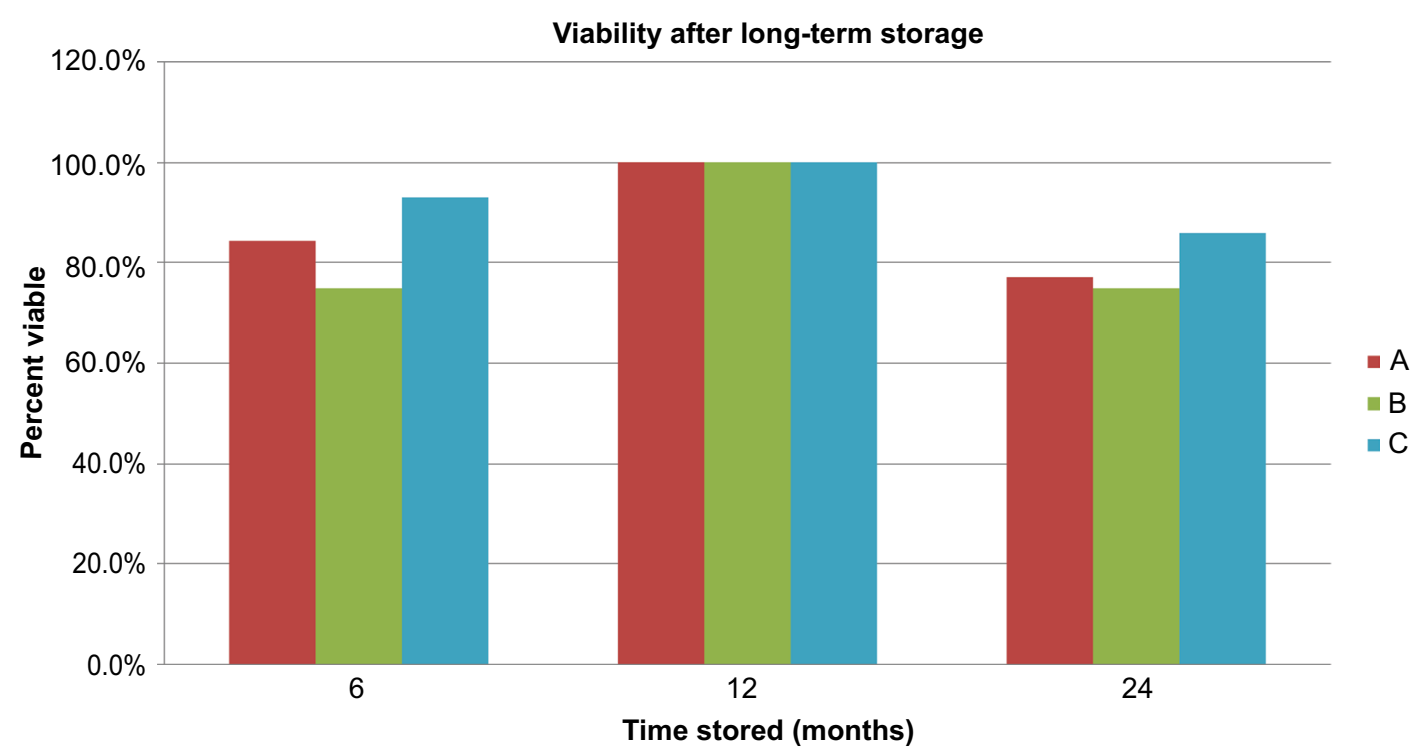

Figure 3 Long-term viability data for adipose stem cells cryopreserved and banked for 2 years.

Notes: Three independent samples (A, B, and C) are shown in comparison. Samples were collected, processed, banked, and thawed. Viability was determined by Trypan blue dye exclusion after being frozen and thawed for I day, which was initially $~ 85 \%-100 \%$. No significant differences were found between any of the time points for a particular sample. 


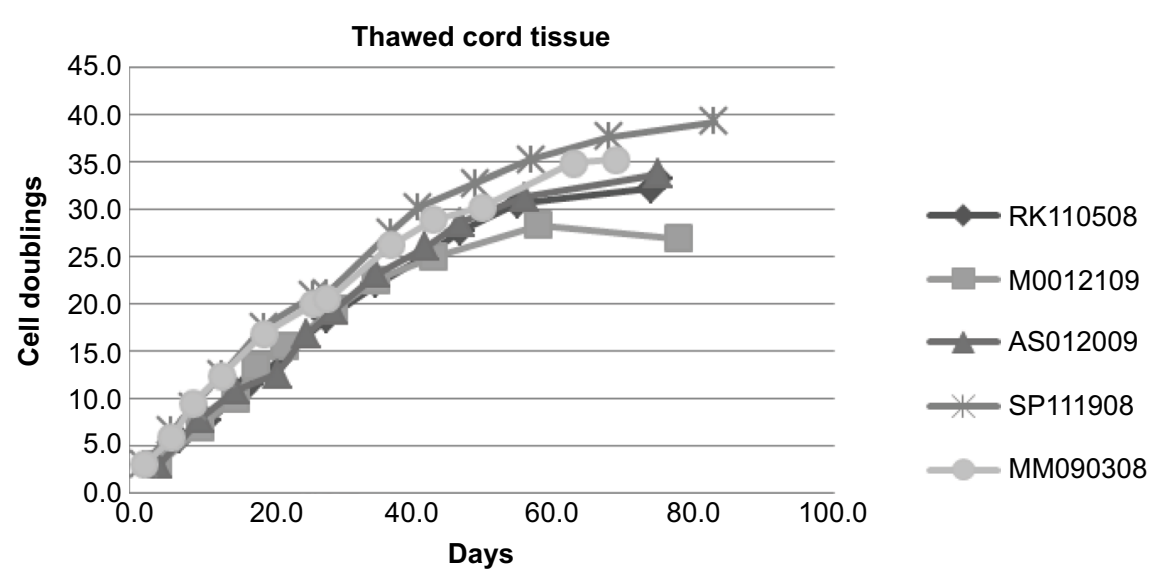

Figure 4 Long-term functional data for CT-MSCs.

Notes: Five independent samples are shown. CT-MSCs were stored for a period of 12 months before thawing and assessment.

Abbreviation: CT-MSC, cord tissue mesenchymal stromal cell.

Acquisition of this type of data becomes invaluable when validating the processes of the cell banking facility, which may later be used for regulatory licensure. It also insures that monetary expenditures are not wasted on samples that will not be useful in the future.

\section{Conclusion}

Stem cells are found in different locations throughout the body, with each anatomical site containing a mixture of stem cell types. However, the most frequently utilized sources due to ease of accessibility and reduced costs are those stem cells found in AT, BM (similar to mobilized PBSC), umbilical CB, and CT. Each of these stem cell sources has different requirements during collection, processing, cryopreservation, and storage. For example, BM and PBSC collections are often $>1,000 \mathrm{cc}$, which require extensive volume reduction for efficient cryopreservation. However, umbilical CB collections are generally $<100 \mathrm{cc}$ in size requiring high-efficiency processes in order to recover sufficient stem cells for clinical use. On the other hand, both CT and AT require a different approach in that neither are single cell suspensions that are customary when performing typical stem cell banking. Each of these challenges can be met with different approaches, all with successful outcomes, as has been described herein.

Most importantly, clinically useful stem cell banking requires the implementation of a rigorous quality control system that will provide confidence and assurance to end-users that cryopreserved samples are viable and functional whenever needed, regardless of how far in the future that might be. In addition, these control systems are necessary to acquire the data needed for scientific and regulatory licensure (eg, CAP or CLIA) that can distinguish one biobank from another, assuring its financial survival as well as its usefulness. Stem cells are collected and banked with the goal of $100 \%$ usage (either clinically or for research), which is only possible when such systems are instituted and strictly followed.

\section{Acknowledgments}

The author would like to thank all the physicians, nurses, and patients who have provided each of the stem cell sources over the past 20 years for use in research as well as for clinical applications. Without your participation, the advances that have been made in stem cell banking and the lives that have been saved would not have been possible.

\section{Disclosure}

The author reports no conflicts of interest in this work.

\section{References}

1. McCulloch EA, Till JE. The radiation sensitivity of normal mouse bone marrow cells, determined by quantitative marrow transplantation into irradiated mice. Radiat Res. 1960;13(1):115-125.

2. Becker AJ, McCulloch EA, Till JE. Cytological demonstration of the clonal nature of spleen colonies derived from transplanted mouse marrow cells. Nature. 1963;197(4866):452-454.

3. Thomas ED, Lochte HL, Lu WC, et al. Intravenous infusion of bone marrow in patients receiving radiation and chemotherapy. $N$ Engl $J$ Med. 1957;157(11):491-496.

4. Gatti RA, Meuwissen HJ, Nymegen MD, Allen HD, Hong R, Good RA. Immunological reconstitution of sex-linked lymphopenic immunological deficiency. Lancet. 1968;292(7583):1366-1369.

5. Gluckman E, Broxmeyer HE, Auerbach AD, et al. Hematopoietic reconstitution in a patient with Fanconi's anemia by means of umbilical-cord blood from an HLA-identical sibling. $N$ Engl J Med. 1989;321(17):1174-1178.

6. Harris DT. Experience in autologous and allogeneic cord blood banking. J Hematother., 1996;5(2):123-128.

7. Rubinstein P, Rosenfield RE, Adamson JW, Stevens CE. Stored placental blood for unrelated bone marrow reconstitution. Blood. 1993;81: 1679-1690. 
8. Ballen KK, Verter F, Kurtzberg J. Umbilical cord blood donation: public or private? Bone Marrow Transplant. 2015;50:1271-1278.

9. Kurtzberg J, Kosaras B, Stephens C, Snyder EY. Umbilical cord blood cells engraft and differentiate in neural tissues after human transplantation. Biol Blood Marrow Transplant. 2003;9(2):128-129.

10. Thomson J, Itskovitz-Eldor J, Shapiro S, Waknitz M, Swiergiel J, Marshall V, Jones J. Embryonic stem cell lines derived from human blastocysts. Science. 1998;282(5391):1145-1147.

11. Lee Y-H, Choil KV, Moon JH, et al. Safety and feasibility of countering neurological impairment by intravenous administration of autologous cord blood in cerebral palsy. J Transl Med. 2012;10:58-69.

12. Cotten CM, Murtha AP, Goldberg RN, et al. Feasibility of autologous cord blood cells for infants with hypoxic-ischemic encephalopathy. J Pediatr. 2014;164(5):973-979.e1.

13. Rubin R, Strayer DS. Rubin's Pathology: Clinicopathologic Foundations of Medicine. New York: Lippincott Williams \& Wilkins; 2007:90.

14. Nardi NB, da Silva Meirelles L. Mesenchymal stem cells: isolation, in vitro expansion and characterization. In: Wobus AM, Boheler K, editors. Stem Cells. Handbook of Experimental Pharmacology. New York: Springer; 2006;174:249-282.

15. Delaney C, Heimfeld S, Brashem-Stein C, Voorhies H, Manger RL, Bernstein ID. Notch-mediated expansion of human cord blood progenitor cells capable of rapid myeloid reconstitution. Nat Med. 2010;16(2):232-236.

16. Horwitz ME, Chao NJ, Rizzieri DA, et al. Umbilical cord blood expansion with nicotinamide provides long-term multilineage engraftment. J Clin Invest. 2014;124(7):3121-3128.

17. Choudhery MS, Badowski M, Muise A, Harris DT. Effect of mild heat stress on the regenerative potential of human mesenchymal stem cells. Cytotherapy. 2015;17:359-368.

18. National Marrow Donor Program Donor Guide. Available from http:// Marrow.org. Accessed November 5, 2012.

19. McCullough J, Clay M, Herr G, Smith J, Stroncek D. Effects of granulocyte-colony-stimulating factor on potential normal granulocyte donors. Transfusion. 1999;39:1136-1140.

20. Sohn SK, Kim JG, Seo KW, Chae YS, Jung JT, Suh JS, Lee KB. GM-CSF-based mobilization effect in normal healthy donors for allogeneic peripheral blood stem cell transplantation. Bone Marrow Transpl. 2002;30(2):81-86.

21. Daniele N, Scerpa MC, Rossi C, Lanti A, Adorno G, Isacchi G, Zinn F. The processing of stem cell concentrates from the bone marrow in ABO-incompatible transplants: how and when. Blood Transfus. 2014;12(2):150-158.

22. Sutton DW1, Chen PC, Schmid-Schönbein GW. Cell separation in the buffy coat. Biorheology. 1988;25(4):663-673.

23. Broxmeyer HE, Douglas GW, Hangoc G, et al. Human umbilical cord blood as a potential source of transplantable hematopoietic stem/progenitor cells. Proc Natl Acad Sci U SA. 1989;86(10):3828-3832.

24. Broxmeyer HE, Cooper S, Hangoc G, et al. Human umbilical cord blood: a clinically useful source of transplantable hematopoietic stem/ progenitor cells. Int J Cell Cloning. 1990;8(Suppl 1):76-91.

25. Solves P, Planelles D, Mirabet V, Blanquer A, Carbonell-Uberos F. Qualitative and quantitative cell recovery in umbilical cord blood processed by two automated devices in routine cord blood banking: a comparative study. Blood Transfus. 2013;11(3):405-411.
26. Solves P, Mirabet V, Blanquer A, et al. A new automatic device for routine cord blood banking: critical analysis of different volume reduction methodologies. Cytotherapy. 2009;11(8):1101-1107.

27. Basford C, Forraz N, Habibollah S, Hanger K, McGuckin CP. Umbilical cord blood processing using Prepacyte-CB increases haematopoietic progenitor cell availability over conventional Hetastarch separation. Cell Prolif. 2009;42(6):751-761.

28. Caplan AI. Mesenchymal stem cells. J Orthopedic Res. 1991;9:641-650.

29. Caplan A. Adult mesenchymal stem cells for tissue engineering versus regenerative medicine. J Cell Physiol. 2007;213(2):341-347.

30. Choudhery MS, Badowski M, Muise A, Harris DT. Utility of cryopreserved umbilical cord tissue for regenerative medicine. Curr Stem Cell Res T. 2013;8(5):370-380.

31. Seshareddy K, Troyer D, Weiss ML. Method to isolate mesenchymallike cells from Wharton's jelly of umbilical cord. Methods Cell Biol. 2008;86:101-119.

32. Wang HS, Hung SC, Peng ST, et al. Mesenchymal stem cells in the Wharton's jelly of the human umbilical cord. Stem Cells. 2004;22(7): 1330-1337.

33. Bunnell BA, Flaat M, Gagliardi C, Patel B, Ripoll C. Adiposederived stem cells: isolation, expansion and differentiation. Methods. 2008;45(2):115-120.

34. Choudhery MS, Badowski MS, Muise A, Pierce J, Harris DT. Adipose derived stem cell utility is independent of anatomical harvest site. Biores Open Access. 2015;4(1):131-145.

35. Chow R, Lin A, Tonai R, et al. Cell recovery comparison between plasma depletion/reduction- and red cell reduction-processing of umbilical cord blood. Cytotherapy. 2011;13(9):1105-1119.

36. Rubinstein P, Dobrila L, Rosenfield RE, et al. Processing and cryopreservation of placental/umbilical cord blood for unrelated bone marrow reconstitution. Proc Natl Acad Sci USA. 1995;92(22):10119-10122.

37. Harris DT, Schumacher MJ, Rychlik S, et al. Collection, separation and cryopreservation of umbilical cord blood for use in transplantation. Bone Marrow Transpl. 1994;13(2):135-143.

38. Badowski M, Muise A, Harris DT. Mixed effects of long term frozen storage on cord tissue stem cells. Cytotherapy. 2014;16(9):1313-1321.

39. Choudhery MS, Badowski M, Muise A, Harris DT. Comparison of the regenerative potential of human adipose and cord tissue derived mesenchymal stem cells. Cytotherapy. 2013;15(3):330-343.

40. Choudhery MS, Badowski M, Muise A, Pierce J, Harris DT. Cryopreservation of whole adipose tissue for future use in regenerative medicine. J Surg Res., 2014;187(1):24-35.

41. Simione FP, Daggett PM. Recovery of a marine dinoflagellate following controlled and uncontrolled freezing. Cryobiology. 1977;14(3):362-366.

42. Harris DT. Optimizing cord blood sample cryopreservation. Cytotherapy. 2012;14(3):359-365.

43. Harris DT, Wang J, He X, Brett SC, Moore ME, Brown H. Studies on practical issues for cord blood banking: effects of ionizing radiation and cryopreservation variables. Open Stem Cell J. 2011;2:37-44.

44. Harris, DT. Collection, processing and banking of umbilical cord blood for clinical use. J Bellevue Obstet Gynecol Soc. 2002;18:13-21.

45. Broxmeyer HE, Srour EF, Hangoc G, Cooper S, Anderson SA, Bodine DM. High-efficiency recovery of functional hematopoietic progenitor and stem cells from human cord blood cryopreserved for 15 years. Proc Natl Acad Sci USA. 2003;100(2):645-650.
Journal of Biorepository Science for Applied Medicine

\section{Publish your work in this journal}

The Journal of Biorepository Science for Applied Medicine is an international, peerreviewed, open access journal that focuses on new developments and advances in the emerging and evolving field of biorepository science. This includes biospecimen procurement, processing, preservation, and banking for application to applied medicine. The Journal invites submission of manuscripts which address these aspects in addition to systems logic, clinical throughput and ethical issues pertaining to application of biorepositories and their effects on clinical medicine. The journal is characterized by the rapid reporting of reviews, original research, methodologies, technologies and analytics in this subject area. The manuscript management system is completely online and includes a very quick and fair peer-review system, which is all easy to use. Visit http:// www.dovepress.com/testimonials.php to read real quotes from published authors. 